\title{
Uma experiência com sala de bate-papo (chat) no ensino de língua estrangeira na escola pública
}

\author{
Hélvio Frank de Oliveira \\ UEG \\ helviofrank@hotmail.com \\ Fabrízia Lúcia da Costa Coelho \\ UEG/SEDUC-GO \\ fabrizia_costa@hotmail.com
}

\section{Resumo}

Recursos tecnológicos inovadores disponíveis em escolas públicas podem ser muito bem explorados na prática docente por meio de métodos e metodologias que, de certa forma, proporcionem ao aluno uma ampla rede de oportunidades de (re)configurar seu modo de construir conhecimento em uma língua estrangeira (LE) e com vistas a refletir sobre a própria abordagem de aprender. Nesse contexto, tornase indispensável, além da disposição e reflexão docente para usar a ferramenta, uma postura discente autônoma e ativa diante da aprendizagem para utilizar ambientes interativos e significativos com aplicações de atividades online. Com o objetivo de identificar e analisar as possibilidades de usos da LE (inglês) através da aplicação da ferramenta Omegle.com, um chat aleatório gratuito, que possibilita pessoas de várias partes do mundo interagir em diversas línguas, um experiência foi conduzida em uma escola estadual pública, com uma turma do primeiro ano do ensino médio, em uma cidade do interior de Goiás no primeiro semestre de 2011. Vinte e um participantes utilizaram o bate-papo virtual para interagir na língua proposta com diversas pessoas provenientes de várias partes do mundo. Os dados foram coletados por meio dos seguintes instrumentos: interações/diálogos produzidos via chat, questionário, diários de pesquisador e observações de aulas no laboratório com registro de notas de campo. Os resultados revelam que a proposta, inédita no contexto, foi desenvolvida com bastante entusiasmo pelos 
participantes, que, por meio do chat, puderam aperfeiçoar sua comunicação de modo independente e, com isso, aprimorar seu conhecimento linguístico no idioma de acordo com os próprios investimentos na tarefa.

Palavras-chave: chat Omegle; experiência; aprendizagem; língua estrangeira

\section{Abstract}

The technological aids available in public schools may be used during teaching experiences through methods and methodologies which provide the student an extensive network of opportunities to (re)configure their way of building knowledge in a foreign language, in order to reflect on their own learning approach. From this perspective, beyond the reflection and desire to use these tools, an autonomous and active attitude by the student is essential in order to use significant environments with on-line activities. An experience was conducted with high school first graders at a public school in a country town of the State of Goiás, aiming at identifying and analyzing the possibilities for the use of the foreign language (English) by employing Omegle.com chat tool. This is a free random chat that allows people from all over the world to interact in several languages, Twenty-one participants used the chat to interact in English with several people from different places in of the world. The data include chat dialogues as well as others collected by means of questionnaires, a researcher journal and classroom observation notes. Results show that the experience, which was inedited in this context of investigation, was developed with enthusiasm by the participants who, through the chat, improved their communication in an independent way.

Key-words: Omegle chat; experience; learning; foreign language

\section{Introdução}

Com o advento das novas tecnologias de informação e comunicação (doravante TIC) nos espaços escolares, na condição de professores de línguas, torna-se relevante (re)pensar a prática docente a partir da implementação de novas abordagens e usos desses variados recursos disponíveis e que nos são proporcionados com vistas a auxiliar a dimensão do ensino com foco na construção de conhecimentos linguísticos, sociais e 
culturais. Nesse sentido, observar a existência de artefatos que possam auxiliar a prática docente, de modo a combiná-los com outras ferramentas utilizadas no ensino, pode ser uma tarefa interessante para que eles possam ser aderidos pelo professor em sua abordagem de ensinar línguas.

Nesta pesquisa, as duas ferramentas tecnológicas utilizadas são o computador e a internet. Sabemos que o computador, tido como uma referência comum à palavra tecnologia, em se tratando de processos de ensino e aprendizagem, necessita de reflexão sobre o seu uso, principalmente, quando há uma inserção não planejada dessas máquinas em contextos educacionais e o professor, sem receber qualquer formação específica para lidar com a ferramenta, é movido a utilizá-las (POLESEL FILHO, 2001).

Além disso, sabemos que, conectado à internet, o computador pode ser utilizado para diversos propósitos e ter como consequência a aprendizagem (TEODORO, 1992). Para tanto, é imperativo que o professor, ao instaurar a aplicação da nova TIC como um recurso pedagógico, observe o papel de mediação a que deverá se submeter, a fim de estabelecer metodologias eficazes e inerentes a esse procedimento ao utilizar a ferramenta tecnológica. É relevante, também, o planejamento sobre as possíveis relações da tecnologia adotada no ensino, considerando a realidade e o contexto no qual os alunos estão inseridos. E, por fim, a visão ampliada sobre estratégias de uso do artefato tecnológico oportunizando possibilidades de aprendizagem, interação e construção do conhecimento colaborativo (FONTES, 2002).

Segundo Lévy (1999), em nossa sociedade contemporânea, as novas TIC voltadas à educação precisam desenvolver nos alunos capacidades de comunicação, de trabalhos coletivos e pessoais, ligados a essas novas formas de interação, a fim de que esses agentes encarem toda a aprendizagem como algo essencial para suas vidas. Desse modo, automaticamente, poderemos pensar numa aproximação de ensino de uma língua estrangeira (LE), cuja responsabilidade esteja centrada no aluno, até mesmo porque o computador e a internet fazem parte de seu cotidiano, e merecem, portanto, 
reflexão sobre o seu uso, a fim de adquirir potencialidades comunicativas de conhecimento, aprendizagem e informação.

Sob tais perspectivas, o presente artigo, que se originou de uma pesquisa experimental conduzida com alunos de ensino médio de uma escola pública, busca identificar e analisar as possibilidades de usos da LE (inglês) através da aplicação da ferramenta Omegle.com, um chat aleatório gratuito, por meio do qual pessoas de várias partes do mundo podem interagir em LE (inglês).

\section{2. $O$ computador e a internet no ensino-aprendizagem de LE}

As práticas docentes, com a novidade de qualquer recurso tecnológico, estão sempre à mercê de (re)configuração e integração de modo a tornarem cada vez mais abrangentes as possibilidades e condições de aprendizagem, conforme a riqueza de alternativas que esses instrumentos novos apresentem. No caso específico do computador e da internet, tais ferramentas possuem valiosas atratividades como imagens, cores, efeitos, sons, entre outros recursos, que, certamente, poderão conferir a professores e alunos a eficácia de aprimoramento de suas práticas linguísticas dentro e fora de sala de aula.

Como artefatos pedagógicos e tecnológicos à disposição do professor e do aluno, o computador e a internet tornam-se ferramentas essenciais para propiciar a ponte entre contexto educativo e as necessidades dos alunos em sala de aula de LE, oportunizando-lhes um motivo para aprender o idioma e uma forma de, por meio dele, criar significados. Nesse sentido, o uso dessas tecnologias em sala de aula, desde que haja uma atitude reflexiva e comprometida por parte do usuário, poderá fornecer-lhe a possibilidade de aprender sem ansiedades ou constrangimentos, encorajando-o a uma atitude mais positiva frente ao propósito disciplinar (LÉVY, 1999).

A esse respeito, é importante destacar que, segundo Paiva (2009), o sucesso da aquisição de uma LE depende da 
inserção do aprendiz em atividades de prática social da linguagem. Por essa razão é salutar que professores saibam usar a nova TIC como uma opção metodológica, a fim de que não se leve para a tela os velhos modelos presentes nos primeiros livros didáticos. Tudo isso porque a tecnologia está à disposição da prática do professor e de como esse docente faz uso da prática em seu favor.

Kenski (2006) reconhece que, em alguns contextos escolares, as novas TIC são impostas, por quaisquer que sejam os fatores, sem a devida reflexão e preparação do quadro de profissionais que ali atuam. Entretanto, a autora avalia que seja pertinente que as escolas estejam interligadas à internet, pois é essa tecnologia que potencializa as possibilidades de acesso às informações e à comunicação com todo o mundo.

Se, antes, o uso do computador e da internet nas escolas, a serviço do ensino/aprendizagem, era considerado algo inconcebível, hoje, as ferramentas estão disponíveis e as possibilidades de inserção e engajamento do aprendiz no ambiente virtual configuram-se com variadas opções de uso.

A internet, por meio da World Wide Web, e inicialmente pelo uso de simples e-mails, tornou-se último de uma lista de avanços tecnológicos a serem introduzidos nas salas de aula. No início e meados dos anos de 1990, para usar a internet em um ambiente de uma escola primária era tomar uma atitude ousada para o desconhecido. (PRITCHARD, 2007, p. 14) ${ }^{1}$

De fato, o acesso à grande rede, oportunizou, tanto ao aluno quanto ao professor, uma certa variedade e quantidade de possibilidades de troca e de partilha de experiências. Conforme nos relata Pritchard (2007, p. 15), "por meio do acesso à internet, é possível crianças 'visitarem' lugares e participarem de

\footnotetext{
1 "The internet, by means of the World Wide Web, and initially by the use of simple e-mails systems, has become the latest in a list of technological advances to be introduced into classrooms. In the early to mid 1990s to use the internet in a primary schools setting was to take a bold move into the unknown". (PRITCHARD, 2007, p. 14)
} 
eventos que de outra forma seria muito longe, muito perigoso, ou caro demais", .

Com as modificações que vêm ocorrendo nos espaços educacionais como um todo, com a chegada dos computadores a algumas escolas, por exemplo, torna-se relevante que $o$ professor se disponha a reconhecer e a lidar com esses recursos. Para tanto, é necessário que o professor esteja atualizado quanto às novas tecnologias que aparecem na escola, a fim de que, na condição de facilitador, ele esteja apto a fornecer e a desenvolver o devido gerenciamento e monitoramento de atividades tecnológicas.

\section{Refletindo sobre papéis docente e discente no uso de novas TIC}

Como podemos prever, em situações de ensino aprendizagem de LE, utilizar uma nova TIC demanda uma mudança de postura por parte docente e discente. De acordo com Moran Costas (2000), ao professor é reservada a função de mediador, instrutor e facilitador, buscando desencorajar os alunos a tê-lo como a fonte principal de conhecimento e incentivando esses discentes à capacidade de aprender por sua própria conta, com estímulo a tomadas de decisões sobre o que aprender.

Quando o professor assume esse papel, ao mesmo tempo, ao seu aluno é disponibilizada uma perspectiva autônoma diante da construção do conhecimento. Segundo Paiva (2005), a autonomia consiste na busca e interesse pelo próprio conhecimento, logo, uma atitude fundamental para $o$ desenvolvimento do aprendiz. Sendo assim, fica claro que essa qualidade deve ser promovida em sala de aula pelo professor, com vistas a buscar alternativas de ensino que propiciem independência e busca própria de maneira efetiva por parte do

\footnotetext{
2 "through access to the internet it is possible for children to 'visit' places and take part in events that would otherwise be too far, too dangerous, or too costly" (PRITCHARD, 2007, p. 15)
} 
aluno, já que a "autonomia é uma atitude que demonstra que o aluno assumiu responsabilidade própria por seu processo de aprendizagem" (p. 32).

Como podemos ver, na aprendizagem autônoma, sobretudo no ambiente virtual, o aluno necessita desenvolver o próprio compromisso pela aprendizagem e ter a oportunidade de se tornar um melhor aprendiz, pois ele pode se capacitar para descobrir as próprias limitações e construir, a partir dessa reflexão, seu próprio conhecimento, de modo significativo. Ecoando Palloff e Pratt (2007, p. 105), no ensino de modo efetivo, "[o]s aprendizes virtuais são encorajados a serem mais autônomos, engenhosos e independentes". 3 Continuam os autores,

[...] o processo de aprendizagem transformadora envolvidas na aprendizagem através do uso da tecnologia, de ensino centrado no aluno-online ajuda os alunos a compreender melhor quem eles são como alunos e como aprendem. Em outras palavras, um foco nos alunos, por meio do uso da tecnologia, auxilia-os no desenvolvimento de áreas em que poderia ser mais fracos, portanto, aprender a aprender. (PALLOFF; PRATT, 2007, p. 106)

Diante desse cenário reservado às novas TIC, é importante que haja uma ruptura na forma de o aluno conceber o processo de aprendizagem de uma LE. Além disso, é necessário o reconhecimento docente de que as inovações tecnológicas estão cada vez mais instaladas nas práticas sociais e, não raro, encontrando lugar efetivo em sala de aula. Diante desse quadro, cabe a nós, professores e alunos, (re)pensarmos novas

3 "Online learners are encouraged to be more autonomous, resourceful, and independent - [...]" (PALLOFF; PRATT, 2007. p.105)

4 "[...] the transformative learning process involved in learning through the use of technology, learner-centered online teaching assists students in better understanding who they are as learners and how they learn. In other words, a learner focus through the use of technology assists them in developing areas that might be weaker, thus learning how to learn." (PALLOFF; PRATT, 2007, p. 106) 
abordagens, novas concepções sobre língua, linguagem, ensino de línguas e novas estratégias para conciliar o uso de novas tecnologias em espaços de sala de aula. Sem dúvida, serão passos importantes para múltiplas possibilidades de aplicação didática das ferramentas disponíveis na web para o ensino e aprendizagem de línguas.

\section{O chat Omegle}

Nossa ferramenta tecnológica disponibilizada pela internet diz respeito a um canal de bate-papo on-line denominado Omegle. Segundo a enciclopédia livre virtual, Wikipédia ${ }^{5}$ o Omegle é um website usado para qualquer pessoa comunicar-se com outras pessoas anônimas atráves da internet via chat. O site foi criado por um Americano de 18 anos, Leif KBrooks, que mora em Brattleboro, Vermont, EUA. O Omegle começou a funcionar no dia 25 de Março de 2009.

Ao acessar o site, o usuário tem a opção de começar o bate-papo em tempo real. O serviço escolhe aleatoriamente dois usuários para o chat e uma tela similar a um mensageiro instantâneo se abre para uma conversa reservada, usando os nicks "You" (Você) e "Stranger" (estrangeiro). Por meio de troca de mensagens, com sorte, é possível conhecer novas culturas de pessoas espalhadas pelo globo e conectadas ao site. Caso a conversa não flua, basta clicar no ícone no canto esquerdo inferior para se desconectar e iniciar um novo bate-papo, em pouco mais de um segundo.

A ferramenta tem a opção de projeção de vídeo em tempo real. No entanto, uma vez que os computadores do laboratório do colégio em que foi realizada a investigação não possuíam webcams, esse recurso não foi disponibilizado. E, também, por questões de segurança e resguardo dos alunos adolescentes pesquisados, a professora mentora da pesquisa decidiu que não fossem aceitos os convites para uso de vídeos.

${ }^{5}$ Disponível em: http://pt.wikipedia.org/wiki/Omegle

66 Horizontes de Linguística Aplicada, ano 11, n. 2, jul./dez. 2012 
A predominância de idioma utilizado no site é o inglês, apesar da participação bem diversificada de usuários pertencentes a outras localidades em que não se fala a língua em questão. Geralmente internautas de todo o mundo, de todas as idades, se comunicam, com destaque para os europeus, e a incidência, é claro, pode variar de acordo com o horário. Chineses, suecos, holandeses, americanos e ingleses formam o grupo dominante na página, segundo algumas experiências e relatos de usuários da rede. $\mathrm{E}$ como nosso propósito era a aprendizagem de LE (inglês), os alunos participantes foram orientados que, em caso de a conversa se desviar da língua alvo de aprendizagem, fossem feitas novas investidas para um novo contato e um novo diálogo.

\section{Contextualização da pesquisa}

A pesquisa foi conduzida durante cinco aulas de quarenta e cinco minutos cada, em uma turma de primeiro ano do ensino médio de um colégio estadual público de uma cidade do interior do Estado de Goiás. Ao todo, foram participantes 21 alunos, os quais receberam pseudônimos como forma de preservar a identidade.

Como instrumentos de pesquisa, foram utilizados os corpora, diálogos virtuais dos alunos com os estrangeiros, coletados entre os dias 25 de abril e 09 de maio de 2011 e, em seguida, selecionados os recortes que continham maior número de participação, de informação e de interação dos participantes com seus contatos. Também, por questões de maior familiarização com o chat e com o uso abreviações, optamos pela seleção dos diálogos realizados nas últimas aulas dedicadas à pesquisa. Os corpora foram analisados conforme as recomendações previstas em Marcuschi (1991) sobre os turnos de fala e considerados seus conteúdos de construção na e sobre a língua alvo como pontos de discussão neste texto.

Como professora titular de inglês da turma pesquisada, a autora desta pesquisa participou, ao longo da investigação, como professora-pesquisadora (PP), e utilizou, além dos dados 
coletados das conversas instantâneas, um questionário sobre as atividades propostas, que foi aplicado ao final da pesquisa. Também, um diário de pesquisadora, em que foram pontuados detalhes objetivos e subjetivos do andamento das aulas ocorridas no laboratório de informática e, ainda, observações de aula com registro de notas de campo, com o propósito de registrar as sensações e comportamentos dos alunos durante as conversas utilizando a ferramenta de chat Omegle.

\section{Análise e discussão dos dados}

Uma das grandes surpresas, ao longo da pesquisa, conforme destacadas nos diários, foi perceber a diversidade de informações que os alunos obtiveram por meio da troca de diálogos, bem como a demonstração de autonomia ao usar a língua alvo. Durante as aulas marcadas para esse propósito, tornou-se nítido, talvez por ser a primeira experiência desses alunos nesse caminho, o desejo de construir conhecimento linguístico manejando a própria língua a ser aprendida.

Embora durante o planejamento para essas aulas "diferentes" tenham surgido receios e questionamentos quanto da adesão e da participação dos alunos na atividade proposta, o resultado foi bastante positivo e desenvolvido com bastante tranquilidade e entusiasmo por parte dos alunos. Ao contrário do que previmos, os participantes gostaram bastante de conversar com os estrangeiros utilizando a língua alvo, conforme consta no quadro 5.1.

Quadro 6.1: Avaliação da experiência discente de aprender LE (inglês) utilizando o chat Omegle

\begin{tabular}{|c|c|c|c|c|}
\cline { 2 - 5 } \multicolumn{1}{c|}{} & $\begin{array}{c}\text { Eu amei } \\
\text { :D }\end{array}$ & $\begin{array}{c}\text { Eu gostei } \\
;)\end{array}$ & $\begin{array}{c}\text { Eu não } \\
\text { gostei } \\
:(\end{array}$ & $\begin{array}{c}\text { Eu odiei } \\
: X\end{array}$ \\
\hline $\begin{array}{c}\text { Quantidade } \\
\text { de alunos }\end{array}$ & 9 & 10 & 2 & - \\
\hline
\end{tabular}


Como é possível perceber, a maioria das opiniões relacionadas ao uso da nova tecnologia foi positiva. Dos vinte e um alunos que responderam ao questionário, apenas dois disseram não ter gostado. Curiosamente, esses dois alunos que declararam não simpatizar com a experiência do chat responderam à pergunta seguinte do questionário, pergunta 2, relacionada à possibilidade futura de usar a ferramenta. Assim eles informaram que se pudessem realizar a atividade novamente, em outro lugar e ocasião, o fariam. Assim, com a unanimidade de respostas positivas a essa pergunta, podemos notar que aqueles dois respondentes da pergunta 1, apesar de não terem gostado da atividade em sala devido à dificuldade especial que possuem com a língua a ser aprendida, relataram que poderiam repetir a conversa com as pessoas estrangeiras em suas casas, LAN house, ou outros lugares.

Em relação aos desafios apontados pelos alunos ao utilizar a ferramenta tecnológica, a maioria considera que a tarefa foi fácil. Nesse sentido, de acordo com as observações de aulas, pudemos verificar que a experiência rendeu-lhes oportunidade de ampliar vocabulário em LE (inglês), de pensar mais diretamente no idioma, de adequar-se ao contexto, no caso, ao uso comum de abreviações previstas na linguagem rápida virtual. Por outro lado, alguns alunos relataram indícios de dificuldade relativos à necessidade de "traduzir com rapidez", à "limitação de vocabulário" e à "baixa velocidade da internet", fatos já sinalizados por alguns estudos (FONTES, 2002).

[1] [...] É um pouco complicado ter que escrever em inglês tentando transmitir o que queremos dizer para que eles entendam, mas no final, foi bom saber que a gente consegue. (Isabella-Questionário)

Durante as observações, foi possível detectar um grupo de 21 alunos conectados em rede tendo que responder instantaneamente ao "outro", de outro lado da tela, fato que rendeu um trabalho bastante intenso por parte da professora. Afinal, como mediadora, era ela quem acompanhava ou sanava dúvidas discentes inerentes à própria ferramenta usada, à língua 
veiculada no diálogo, inglês, entre outras dificuldades que os alunos poderiam vir a ter no momento das conversas.

Ao mesmo tempo, cabe relatar que muitos possuíam atitudes autônomas durante as conversas. Desse modo, muitos usaram o tradutor Google para auxiliá-los quando não entendiam uma palavra, outros recorriam aos próprios colegas do lado, e até mesmo tentavam negociar significados em língua com o estrangeiro buscando se comunicarem efetivamente.

De fato houve interessantes usos reais da língua durante a experiência efetivada em aulas de LE (inglês), em que a estrutura e o sistema linguístico ficaram subordinados ao uso, à troca de informações como instrumento de interação entre interlocutores reais. O benefício de uma proposta funcional e comunicativa de ensino de línguas, de acordo com Pritchard (2007), é que os erros gramaticais são postos em segundo plano, pois não são eles os determinantes na comunicação, na combinação de sentidos estabelecidos. Aliás, mesmo com esses equívocos, foi possível comunicação efetiva entre os pares, como podemos ver na conversa do Roberto com o seu par estrangeiro:

\author{
[2] \\ Stranger: hi? \\ You: where hi lives \\ You: I live in Brazil \\ Stranger: wow \\ Stranger: $i$ live in china \\ You: $m / f$ \\ You: china \\ Stranger: $m$ \\ You: $m$ \\ You: Legal \\ Stranger: what legal? \\ Stranger: so how old are you \\ You: China quite far from Brazil \\ You: 18 \\ Stranger: yea \\ You: age \\ You: and you
}


You: age??

(Conversa de Roberto com um estrangeiro/parte 1)

$\mathrm{O}$ aluno Roberto utilizou em sua pergunta "Where $h i$ lives" uma construção equivocada em termos gramaticais, quando o correto seria usar "you" ao invés de "hi", observandose a enunciação do diálogo e a referenciação correta. Todavia o aluno participante seguiu afirmando que vivia no Brasil, ou seja, a intenção dele foi declarada com a própria investida fática de responder à mesma pergunta produzida ao parceiro virtual. Assim as informações pretendidas ficaram implícitas para esse interlocutor estrangeiro e a própria agilidade do contexto induziu-o a uma resposta, isto é, a comunicação tornou-se satisfatória ao cobrir a lacuna gramatical sem prejuízos de entendimento.

Também, com a interação e a colaboração propostas pela conversa virtual, o aluno pôde aprender aspectos sobre a cultura e a diversidade do outro, descobrir o que ele pensa, do que ele gosta, entre outras questões de identidade e diferença. Acreditamos que essa experiência de compreender a cultura do outro se somou à formação do aluno e também passou a ser um diferencial e uma motivação própria e implícita, empregando, é claro, a língua-alvo, na atividade.

\author{
[3] \\ Stranger: the only thing $i$ know about brazil is that you \\ guys are very good at football \\ Stranger: 17 \\ You: and are even only in football \\ You: ta weak economy \\ Stranger: $i$ don't know, it's a kind of sterotype \\ You: you play football \\ Stranger: nope.. \\ Stranger: i prefer swimming \\ Stranger: what about you \\ You: I play soccer every day \\ You: sao paulo \\ Stranger: then you must be very good at it \\ You: Sao paulo soccer club
}


Stranger: you are a club member?

You: team player profissinal

Stranger: wow..

(Conversa de Roberto com um estrangeiro/ parte 2)

No diálogo acima, o falante estrangeiro, no seu turno, manifesta um estereótipo muito comum acerca do Brasil que é o profissionalismo no futebol. Roberto, de imediato, procura responder que essa marca se dá no âmbito apenas do esporte, reforçando o estereótipo. O participante incrementa que, na economia, nosso país é fraco: "ta weak economy". A conversa flui de maneira tranquila, eles conversam sobre algo do cotidiano deles, Roberto menciona que gosta de futebol e confessa já ser um "profissional" da modalidade, enquanto seu interlocutor diz não saber jogar futebol, preferindo natação. Outro detalhe interessante que se nota em três turnos de fala é que os interlocutores usam o termo football - futebol americano, para construir o significado desejado, sem perceber o termo exato ao qual poderia designar o futebol da cultura brasileira, mas, também, sem prejuízo na comunicação. Depois, mais no fim da conversa sobre hobbies, em que há troca de informações baseadas na negociação e cooperação entre os pares, Roberto declara que "I play soccer" (Eu jogo futebol), sustentando a ideia do desporto mais popular do Brasil e declarando ao estrangeiro a modalidade a que se referiu.

O excerto seguinte traz uma conversa de Isabela com um emblema de cooperação entre os interlocutores:

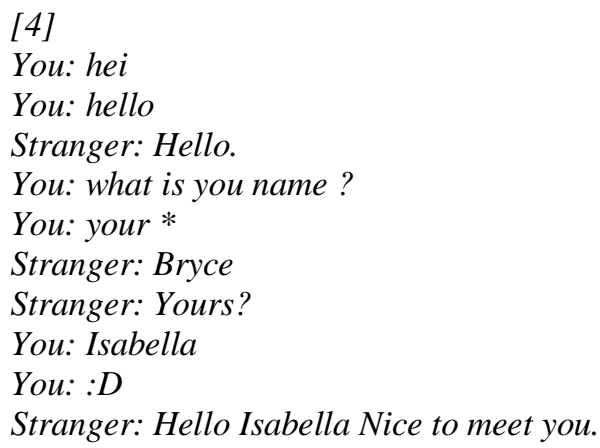


Hélvio F. de Oliveira e Fabrízia L. C. Coelho

Stranger: Where abouts do you live?

You: i'm brazilian, its you?

Stranger: No sorry im aussie

Stranger: Whats the weather like over there lately?

You: I'll take answer a bit, I have to translate

You: :S

You: :s

You: kkkkkkk

Stranger: Hello?.

Stranger: ok.

You: I do not understand much English

You: so it takemanejars me to answer

Stranger: That's ok sweetie :)

You: *

You: how old?

Stranger: 17 yourself?

You: $15 *_{-} *$

Stranger: Aww cute

Stranger: Whats other Languages do you speak?.

You: portugues only ;

You: $k$ k

You: its you?

Stranger: Nah i only speak english.

You: ooooooook *-*

You: study?

Stranger: Nope

Stranger: You?

You: yes, I'm at school

Stranger: Do you have a cute school uniform?

You: I do have, is nothing more beautiful :/

Stranger: can i see a picture?

You: I'm at school, I have no picture here ;s

You: you work?

Stranger: yeah 4 days a week

You: ooooooook *-*

You: bye

You: kiss :*

(Conversa de Isabela com um estrangeiro)

A aluna, mesmo tendo dificuldades em compreender algumas frases produzidas pelo parceiro virtual, busca meios de 
manter o diálogo, explicando suas limitações ao interlocutor: "I don't understand much english"/"so, it takes to answer" - "Eu não entendo muito inglês"/ "demoro responder". Interessante observar também que Isabela, mesmo enfrentando obstáculos, não desiste de investir e buscar a negociação de sentido. Com isso, ela se mostra totalmente ousada e tem o maior número de turnos em comparação a seu interlocutor. Inclusive, ela responde às questões, comenta sobre o uniforme da escola, e ainda pergunta: "its you?"/ "how old?"/ "you work?" - "E você?"/ "Qual idade?"/ "Você trabalha?".

Com a produção dessas perguntas/turnos, ainda que comprometidas, fica clara a atitude da aluna de tentar ser compreendida e entender o que o outro quer dizer. De maneira alguma, ela se mostra passiva e alheia às perguntas, pelo contrário, mantém uma postura ativa e deseja que o seu interlocutor seja solidário e a ajude a desenvolver habilidades de comunicação. Em muitos momentos como esse, durante as observações, pudemos perceber que o aumento de vocabulário e a construção de conhecimentos, inclusive, culturais, foram bastante satisfatórios. Até mesmo porque alguns alunos, após a aula experiência, comentavam informalmente com a professora detalhes nesse sentido.

Com esses indícios de colaboração no desenvolvimento de uma tarefa virtual, conforme sinaliza Paiva (2009), e desde que os pares se comprometam com a tarefa e tenham interesse por ela, pode haver um excelente ganho na aprendizagem de conteúdo a que se destina, no caso desta pesquisa, uma melhoria vocabular em um idioma estrangeiro.

Ademais, a autonomia, imbuída de motivação, permite essa busca pela realização e efetivação da comunicação. Aliás, é a predominância dessa característica somada à linha de interesses dos usuários do chat ao desenvolver um diálogo virtual que fortalecem a conversa e dão qualidade à interação produzida. Em outras palavras, o assunto sobre o qual conversam, o motivo pelo qual conversam sobre determinado assunto e a qualidade de informações são itens que devem ser bastante coerentes, negociados e atrativos durante esse tipo de comunicação instantânea.

74 Horizontes de Linguística Aplicada, ano 11, n. 2, jul./dez. 2012 
Como vimos, trabalhar com chat em aulas de LE (inglês) pode ser uma estratégia de ensino viável para produzir, de maneira ativa, o conhecimento de novos vocábulos, bem como o reconhecimento de itens específicos da linguagem virtual. Nesse caso, há devida importância de o aluno também buscar uma postura autônoma para a condução da tarefa e ter consciência colaborativa sobre o uso dessa linguagem. $\mathrm{O}$ ganho durante a interação virtual via chat, como se pode notar, será cognitivamente duplo: em língua, por conta das amostragens e testes feitos para construir as sentenças e experimentar os vocábulos lançados em tempo real como forma de perguntas, afirmações, negações. E, em conhecimentos culturais, pela curiosidade de saber quem é o outro, como ele se sente, o que ele faz, seja por vontade, por necessidade ou por qualquer outro motivo.

A seguir, apresentamos uma conversa de Carlos com um estrangeiro:

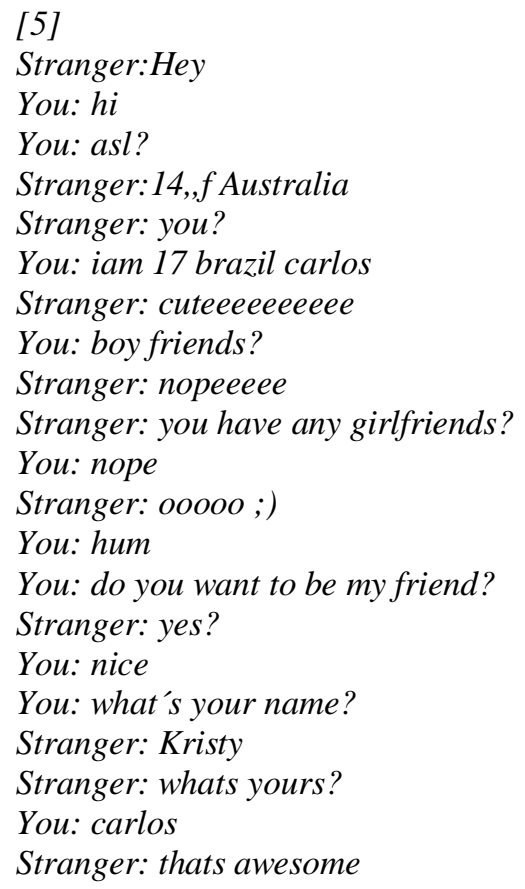


You: thanks

You: you is nice

Stranger: thank you

(Conversa de Carlos com uma estrangeira)

Podemos notar que o aluno e a estrangeira trocaram algumas informações básicas sobre idade, sexo, localidades e relacionamento amoroso. Depois de decidirem ser amigos virtuais, o aluno manifesta que a australiana é legal e a conversa finaliza. Grosso modo, aqui, a comunicação, ainda que seja desenvolvida com elementos básicos de saudações, de agradecimentos, entre outros tópicos previstos nas primeiras curiosidades do gênero discursivo chat, é produzida de modo original, espontânea e natural, uma vez que o assunto desencadeia-se sem previsões. É a partir das perguntas que os interlocutores dão seguimento ao tema e o desenvolvem.

Também, com base no excerto anterior, é notável que as experiências de cinco aulas dos participantes utilizando a ferramenta tecnológica Omegle permitiram que eles próprios, por meio da interação com outros estrangeiros, aprendessem alguns códigos, símbolos e sinais típicos da linguagem virtual. Por exemplo, "asl", que seriam as abreviações iniciais das perguntas "age, sex, location?" - idade, sexo e local de origem, cuja resposta "f.", dada pela estrangeira, significaria "female" feminino.

Cabe ressaltar que esclarecimentos quanto à linguagem virtual em LE (inglês) e o uso de emoticons foram explicitados durante uma das aulas para que os alunos entendessem a que se referiam e, durante o diálogo, caso aparecesse algum desses itens e até mesmo alguns novos, eles compreendessem o seu sentido. Vejamos a conversa de Caio com uma estrangeira:

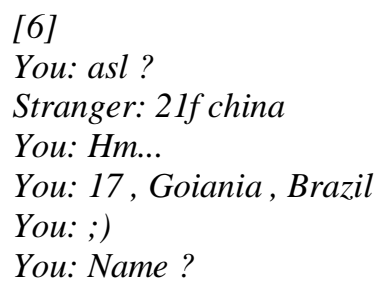


Hélvio F. de Oliveira e Fabrízia L. C. Coelho

Stranger: chinese?

You: Portuguese, English

Stranger: ivy

You: $\mathrm{hm}$

You: What Your name?

Stranger: ivy

You: name beautiful

Stranger: thank you

You: my name is PeduRamu

Stranger: $o$

Stranger: ${ }^{\wedge} \wedge$

You: ;)

You: $m / f$ ?

Stranger: nice to meet you

Stranger: $f$

You: nice to meet you

You: :D

Stranger: $\wedge \wedge$

Stranger: haha

You: hehe

Stranger: 0.0

You: kkk osama bin laden, -.--

You: lol

Stranger: ...

You: death!

You: dead*

Stranger: 0.0

You: Changing the subject, you enjoy some sort of music?

You: I enjoy house music

Stranger: hip hop

You: Nice, nice

You: FUNK!!!!

Stranger: 0.0

You: auhsuhsuashaushs

You: Rap

Stranger: yoyo

Stranger: haha

You: use e mail, facebook, twitter, skype, ts?

Stranger: email

You: hum. use email .. 
You: nice to meet you, good bye

Stranger: bye

(Conversa de Caio com uma estrangeira)

Com base na conversa de Caio, excerto anterior, é possível notar que as abreviações se tornaram bastante funcionais no diálogo virtual. Aos poucos os alunos se engajam de maneira tão extraordinária que passam a utilizá-las eficazmente, sem embaraços. Ademais é característica da linguagem virtual as falas rápidas e objetivas, de preferência, com menos estruturação sintática e com ênfase nos lexemas: "Name?" ao invés de "What is your name?"; "Chinese?" ao invés de "Are you chinese?"; e também de omissões de auxiliares em perguntas: "use e mail, facebook, twitter, skype, ts ?" ao invés de "Do you use e-mail, facebook, twitter, skype, $t s ?$ ?.

Por outro lado, se o participante da pesquisa não utilizou a língua com rigores gramaticais, no plano de coesão, ele o faz muito bem com o uso da coerência firmada pelo uso de marcadores de discurso ao avisar à parceira virtual sobre a mudança de assunto: "Changing the subject, you enjoy some sort of music?". Com essa fala, ele dá seguimento à conversa e inicia outro tópico depois de comentar e encerrar o assunto sobre a morte de Bin Laden.

Em se tratando de equívocos, os quais, vale salientar, não prejudicaram a comunicação, temos o uso de adjetivo antes do substantivo por parte de Caio na frase de opinião sobre o nome da estrangeira: "name beautiful"/ "nome bonito". São itens funcionais cujos detalhes sintáticos geralmente não são motivos de discussão ou quebra do bate-papo, a menos quando a informação postada produza duplo sentido ou não seja compreendida por um dos interlocutores, os quais, normal e automaticamente, perguntam sobre a dúvida.

Com o encerramento da experiência, notamos que boa parte dos relatos dos alunos da turma sugeriu uma experiência positiva ao usar a ferramenta tecnológica. Dezoito participantes responderam que utilizar o chat para aprender inglês os ajudou 
no aprimoramento do idioma, enquanto apenas três disseram "não" terem tido uma experiência válida.

Diante disso, as principais justificativas de viabilidades relatadas pelos participantes no questionário foram: ampliação do vocabulário, inglês usado de forma real e a colaboração do outro na tarefa. Por sua vez, a única inviabilidade assinalada foi o fato de algumas conversas não durarem tempo suficiente para construir significados, uma vez que alguns contatos desistiram imediatamente de conversar com alguns participantes e encerraram a conversa.

\section{[7] Algumas conversas não duram um minuto (Carlos)}

[8] [...] envolvendo com outras pessoas você aprende mais. (Isabela)

Além disso, a experiência de uso do chat Omegle evidencia a importância de utilizar o computador e a internet como recursos em sala de aula de LE (inglês). São ferramentas interessantes das quais o aluno pode fazer uso e, com isso, aprender um novo idioma em ambientes virtuais. No caso deste experimento, os alunos puderam conversar em poucos minutos com um chinês e, depois, com um australiano, sem saírem do lugar. O chat funcionou como uma ferramenta eficaz no processo de aprendizagem em LE (inglês), propiciando aos usuários uma oportunidade de interagir com uma pessoa do "outro lado" do mundo, explorando nessa construção a própria linguagem.

Isso pode ser evidenciado na fala de Isabela, ao considerar a importância do interlocutor que fala a LE (inglês) e a tem como requisito importante no processo de ensino e aprendizagem. Semelhantemente, não há nenhuma negociação em língua materna e, no caso, a aluna prioriza o uso da língua alvo para efetiva comunicação:

[9]A gente aprende mais conversando com pessoas que falam a língua inglesa" (Isabela) 


\section{Considerações finais}

Ao trabalhar com uma ferramenta tecnológica para a produção de conhecimentos em uma LE, a aprendizagem foi consolidada por meio de atitudes discentes ativas ao longo do processo, uma vez que a maior parte dos alunos se dispôs a tornar-se responsável por seu próprio investimento na tarefa, ativa diante do conhecimento a ser produzido. $\mathrm{O}$ resultado foi a negociação de dúvidas e a busca pelo conhecimento linguístico por si próprio, pela vontade, pela necessidade e pela interação.

Nessa mesma proporção, a aprendizagem da LE só fez sentido para o aluno quando a professora, conforme determinam alguns estudiosos (KENSKI, 2006; PAIVA, 2009), no papel de mediadora, oportunizou atividades de uso real, concreto e social do idioma. Com isso, boa parte dos alunos ficou imersa num ambiente em que era possível interagir de maneira independente e eficaz, garantindo o próprio investimento na tarefa.

$\mathrm{O}$ experimento durante aulas de LE (inglês) consistiu apenas numa tentativa de observar o que se tornou viável ou não em termos de uso do computador e da internet como recursos à disposição de professores de LE (inglês). Ao usarem o chat, o formato de aula rompeu com a condição tradicional e esquemática de ensino e valorizou a própria ação do aluno em investir em sua aprendizagem. As ações em sala com a proposta efetivada reconfiguraram-se com a autonomia e maior participação do aluno como agente do seu próprio conhecimento, ou seja, os alunos foram o foco e a professora teve o papel de facilitadora no processo de ensino/aprendizagem.

Ressaltamos que a maioria dos alunos investiu na tarefa de modo autônomo, fato que propiciou a busca por soluções práticas durante a produção do bate-papo, isto é, durante a construção de sentidos para as interações e comunicação em tempo real em LE. Ademais, por meio dos relatos, pudemos visualizar a importância de aprender uma LE com foco no uso e não na gramática do idioma, uma vez que a comunicação no idioma era a exclusiva prioridade no processo. 
Sem dúvida, a experiência causou a quebra de paradigmas tradicionais equivalentes à figura secular do professor como norteador de toda prática pedagógica. Com isso, houve a reconfiguração da abordagem de ensinar, sem desconsiderar o importante papel da professora. Sua função descentralizada, de mediadora e facilitadora no processo de ensino, tornaram seus alunos mais independentes e ativos com a experiência.

Embora essa proposta tenha sido uma experiência, até mesmo para observar como os alunos desenvolveriam o que foi previamente planejado pela professora, hoje, nossa prática tem sido balizada por esses e outros recursos tecnológicos, o que favorece um avanço maior nas condições de ensino. Em sala de aula, temos visto que esses benefícios se configuraram na disposição dos alunos para utilizar novas TIC e, portanto, novas formas de aprender, observando que o ensino aprendizagem de uma LE não ficará restrito em se tratando dos mais variados recursos disponíveis ao professor. Lembrando sempre que, para fazer uso de qualquer equipamento ou ferramenta tecnológica, cabe ao professor, mediador, reflexão e conhecimento prático sobre o recurso.

\section{Referências}

FONTES, Maria do Carmo M.. Aprendizagem de inglês via internet: descobrindo as potencialidades do meio digital. 2002. $217 \mathrm{f}$. Tese (Doutorado em Linguística Aplicada ao Ensino de Línguas) - Pontifícia Universidade Católica de São Paulo, São Paulo, 2002.

LÉVY, Pierre. Cibercultura. São Paulo: Editora 34, 1999.

KENSKI, Vani M. Da escola presencial à escola virtual. In: . (Org.). Tecnologias e ensino presencial e à distância. 3 ed. Campinas: Papirus, 2006. p. 53-68. 
MARCUSCHI, Luiz Antônio. Análise da conversação. São Paulo: Ática, 1991.

MORAN COSTAS, José Manuel. Mudar a forma de ensinar e de aprender com tecnologias. Interações (Universidade São Marcos), São Paulo, v. V, n. 9, p. 57-72, 2000.

PAIVA, Vera Lúcia M. O. Autonomia e complexidade: uma análise de narrativas de aprendizagem. In: FREIRE, Maximina M. VIEIRA-ABRAHÃO, Maria Helena.; BARCELOS, Ana Maria F. (Org.). Lingüística Aplicada e contemporaneidade. Campinas, SP: Pontes Editores, 2005. p. 135-153.

- O uso da tecnologia no ensino de línguas estrangeiras: breve retrospectiva histórica. Disponível em: <http://www.veramenezes.com/techist.pdf.> Acesso em $28 \mathrm{de}$ jun. 2009

PALLOFF, Rena; PRATT, Keith. Building learning communities in cyberspace: effective strategies for the virtual classroom. San Francisco: Jossey-Bass Publishers, 2007.

PRITCHARD, Alan. Effective teaching with internet technologies. London: SAGE Publications Company, 2007.

TEODORO, Victor D. Educação e computadores. In:

FREITAS, José C. (Org.). Educação e computadores. Lisboa: GEP/ME, 1992. p. 9-25.

Recebido em: 23/01/2012

Aceito em: 12/03/2013

Title: Experiencing the use of a chat room in EFL teaching in a public school 